\title{
REVIEW
}

\section{A Review of Research on Ecological Economics Based on Bibliometrics}

\author{
Yin Huang ${ }^{1} \mathrm{Na} \mathrm{Li}^{1}$ Guoqin Huang $^{1^{*}}$ Huifang $\mathrm{Xu}^{1,2^{*}}$ \\ 1. Ecological Science Research Center, Jiangxi Agricultural University, Nanchang, 330045, China \\ 2. Key Laboratory of Crop Physiology, Ecology and Genetic Breeding, Ministry of Education/Jiangxi Province, \\ Jiangxi Agricultural University, Nanchang, 330045, China
}

\section{ARTICLE INFO}

Article history

Received: 3 September 2021

Accepted: 22 September 2021

Published Online: 27 September 2021

\section{Keywords:}

Ecological economy

Industrial ecology

Bibliometric analysis

Citespace

\begin{abstract}
The development of ecological economics is a major strategy for development in the 21 st century. Although scholars have been rising more and more interesting for ecological economic over the past 10 years, it is still unclear what is the change will be facing in the future. In order to provide a theoretical basis for the future development of ecological economy, our article analyzes the current research progress of ecological economy on the basis of a bibliometric analysis. The results show that (1) sustainable development of an ecological economy is a hot research topic; (2) there is little cooperation and exchange between institutions and among scholars regarding ecological economics; (3) the number of publications on ecological economics is increasing, with a relatively large number being published in China. Therefore, we must strengthen the cooperation between institutions and among scholars and improve the research content, vision, and methods in this field. This study provides a theoretical basis for the future development of ecological economy.
\end{abstract}

human beings focused on economic development issues and ignored the relationship between the ecological environment and economic development, which led to severe environmental pollution problems, environmental damage, and a serious waste of resources. Therefore, to solve the problem between the ecological environment and economic development, scientists put forward the concept of "ecological economics" in the early 1960s. The development of ecological economics has been a significant strategy in the 21 st century ${ }^{[2]}$.

From the 1960s to the 1970s, the unified point of view

\footnotetext{
*Corresponding Author:

Guoqin Huang,

Ecological Science Research Center, Jiangxi Agricultural University, Nanchang, 330045, China;

Email:hgqjxes@sina.com

Huifang Xu,

Ecological Science Research Center, Jiangxi Agricultural University, Nanchang, 330045, China; Key Laboratory of Crop Physiology, Ecology and Genetic Breeding, Ministry of Education/Jiangxi Province, Jiangxi Agricultural University, Nanchang, 330045, China; Email:xhuifang@yeah.net
} 
between the new classical economic theory ${ }^{[3]}$ and natural scientists was that technology alone could not solve population and pollution problems. The contradiction between the ecological environment and the economy can be solved effectively by adopting ethical laws and economic adjustment measures. Since the 1970s, scientists have done much work on the theory and application of the restoration and reconstruction of disturbed and damaged ecosystems. The report "There Is Only One Earth," published in $1972{ }^{[4]}$, focused on the earth's future. It analyzed today's environmental problems from social, political, and economic perspectives. It reported on the rapid population growth, waste of resources, the impact of industry and technology, unbalanced development, and the dilemma of urbanization worldwide and revealed why human environmental resources have been destroyed and the global ecosystem were damaged to remind people of the finiteness and changeability of living places. Currently, we systematically study the origin of the ecological system's restrictions on humans ${ }^{[5]}$. In 1986, Vitousek combined the primary production capacity and carrying capacity of the natural system, and people began focusing on the ecological system's constraints on the human system and discussing the ecological carrying capacity of human society ${ }^{[6]}$. In 1987 , some scholars proposed a combination of economy and ecology ${ }^{[7]}$. The ecological environment and economy are interdependent and mutually promoting. The higher the degree of coordination, the more probably sustainable development can be achieved ${ }^{[8]}$. The International Society for Ecological Economics (ISEE) was established in the late 1980s and was founded by more than 50 scientists. After founding ecological economics, they began the "Ecological Economics" magazine in 1989, formally establishing ecological economics. In 1991, Pearce divided the development into two categories; strong sustainability, and weak sustainability given the difference in the treatment of natural assets and artificial assets, which can be regarded as a milestone in the study of sustainable development indicators. However, China proposed the study of ecological, economic issues and established ecological economics in 1980. China's ecoeconomic development is divided into five stages: the first stage was of poor development from 1985 to 1992 , the second stage from 2003 to 2009 , the third stage performed well in the early stage of reform (1981-1984), the fourth stage was from 1993 to 2002, and the fifth phase was from 2010 to $2012^{[9]}$. Research on the highquality development of the ecological economy has emerged in academic circles, mainly from the connotation of the ecological economy and green development, the model and development path of the ecological economy, etc. ${ }^{[10]}$. Different research methods for the sustainable development of regional ecological economics exploring the coordinated development and green and lowcarbon cycle level have attracted substantial political and policy attention ${ }^{[1]}$. Nowadays, China's economy is shifting from high-speed growth to high-quality development, striving to achieve a coordinated social economy and ecological environment ${ }^{[12]}$. At present, some studies have carried out high-quality research in the ecosystem and ecological security, high-quality economic development and its driving forces, and achieved a series of research achievements. China is in a critical period of transformation of the economic development mode, and regional ecological carrying capacity and economic growth are rapid. The contradiction between the bearing capacity of a region and ecological development is still prominent, and a contradiction between ecology and economy still exists. Domestic and foreign scholars have conducted many useful explorations and studies on the coordinated development of the ecological environment and economy. Scholars such as Suo Cheng analyzed the distribution pattern of resources, ecological environment, and social economy of the Silk Road Economic Belt in 2015 and proposed the main models and paths for the sustainable economic development of the Silk Road Economic Belt. In 2018, Song analyzed the coordinated development of the social economy and ecological environment in the Weihe River Basin. Tian used simulation models to analyze developed cities in 2019 and predicted the possible interaction between the urban economy and the ecological environment ${ }^{[13]}$.

Discussing the research hotspots and frontiers in this field at home and abroad is conducive to grasping the latest progress of ecological economic research and can provide literature references for follow-up related research. To gain a deeper understanding of the research hotspots in ecological economics, this study uses a scientific measurement method and CiteSpace to visualize the scientific knowledge map. It analyzes the development status of the ecological economy research field at home and abroad, from keywords, research institutions, and authors, to introduce the relevant information of the main research and analyze the main hot topics.

\section{Data Sources and Analysis Methods}

In this article, data in the field of ecological economy are obtained from the Web of Science database, with the theme of "Ecological Economy", the time range of "2011$2020 "$, and the Index: topic = ("ecological economy"). After searching and sifting conference records and book 
chapters, 3074 papers were obtained. And we found that several related keywords included, such as ecological economics, industrial ecology, ecological modernization and so on.

We exported the searched documents to a plain text format through the search results obtained in the Web of Science database. We then imported the data into the CiteSpace software for analysis to draw a keyword co-occurrence map, a keyword cluster map, a keyword emergence intensity cluster map, a keyword Timeline map, a published author map, and a diagram of institutional cooperation. In the CiteSpace software toolbar, select Import/Export to enter the Data Processing utility page, click WOS, select the corresponding folder in the Data Directories, and then the WOS column. Click Remove Duplicates from 2011 to 2020 in ecological economics. The data of the number of posts issued by Excel are processed to obtain the post trend chart (Figure 1).

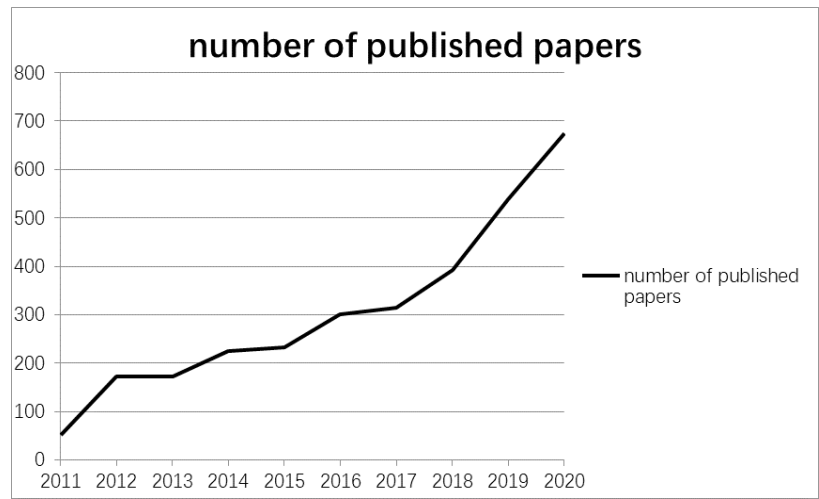

Figure 1. Trends of publications in the research field of ecological economy from 2011 to 2020

\section{Results and Discussion}

\subsection{Analysis of the Number of Papers}

By analyzing the retrieved documents in CiteSpace, the number of papers published on ecological economics from 2011 to 2020 was obtained, and a line chart of the publication trend was made using Excel (Figure 1). Through the broken line, we found that from 2011 to 2020 , the number of published documents in ecological economics has shown an increasing trend. However, the period from 2011 to 2017 was a slow development stage with a slight increase. Overall, there was a rapid development trend from 2017 to 2020. From 2011 to 2020 , the number of hot spots in ecological economics is increasing annually. The number of articles published has increased from more than 50 to nearly 680 .

\subsection{Analysis of Keywords}

We used CiteSpace to construct four maps of ecological economics, namely the keyword co-occurrence map (Figure 2), the keyword key node cluster map (Figure 3), the keyword emergence intensity cluster map (Figure 4), and keyword Timeline map (Figure 5). Figures 2, 3 and 4 show that sustainability is the current research hotspot in ecological economy. The main purpose of studying ecological economy is to deal with the relationship between ecosystems and economic systems. According to the current economy, scientists propose solutions to the existing problems in social development to coordinate the economic society and the ecological system and orderly achieve the goal of sustainable ecological and economic development. Ecological economics has been a longterm concern for human society, which can be seen in the establishment of the international society in 1988 , the formal institutionalization of ecological economics ${ }^{[14]}$. Ecological economics is a discipline that studies the structure, function, and movement laws of the composite system of ecosystems and economic systems and belongs to a branch of economics. It is based on the idea of uniting academicians from different backgrounds, to encourage new ways of thinking about the relationship between ecosystems and economic systems. The development of the ecological economy has always attracted attention. Keywords are the core of the article. By analyzing keywords, we can study the research hotspots within a certain period. According to the keyword co-occurrence map (Figure 2), the number of nodes in the map was 503, the number of connections was 710 , and the network density was 0.0056 . Both the node size and keyword size in the map indicate the frequency of occurrence of a keyword. The larger the value, the higher the frequency of the word, which can be used as a research hotspot for analysis. The keyword that appears most frequently in this research field is sustainability, followed by management, climate change, and impact. According to the key node cluster diagram of keywords (Figure 3), the first ten cluster words are set, namely carbon dioxide emission, metabolic transition, hospitality model, forest carbon project, degrowth activist and circular economy indicating that the current research is mainly focused on sustainable development, paying close attention to the issue of carbon dioxide emissions and look for a sustainable development model. In 2015, the United Nations put forward the 2030 commitment to achieve 17 sustainable development goals and 169 specific goals. These goals are divided into sustainability dimensions in the scientific literature: economic, social, and environmental ${ }^{[15,16]}$. Thoroughly

DOI: https://doi.org/10.30564/re.v3i3.3685 

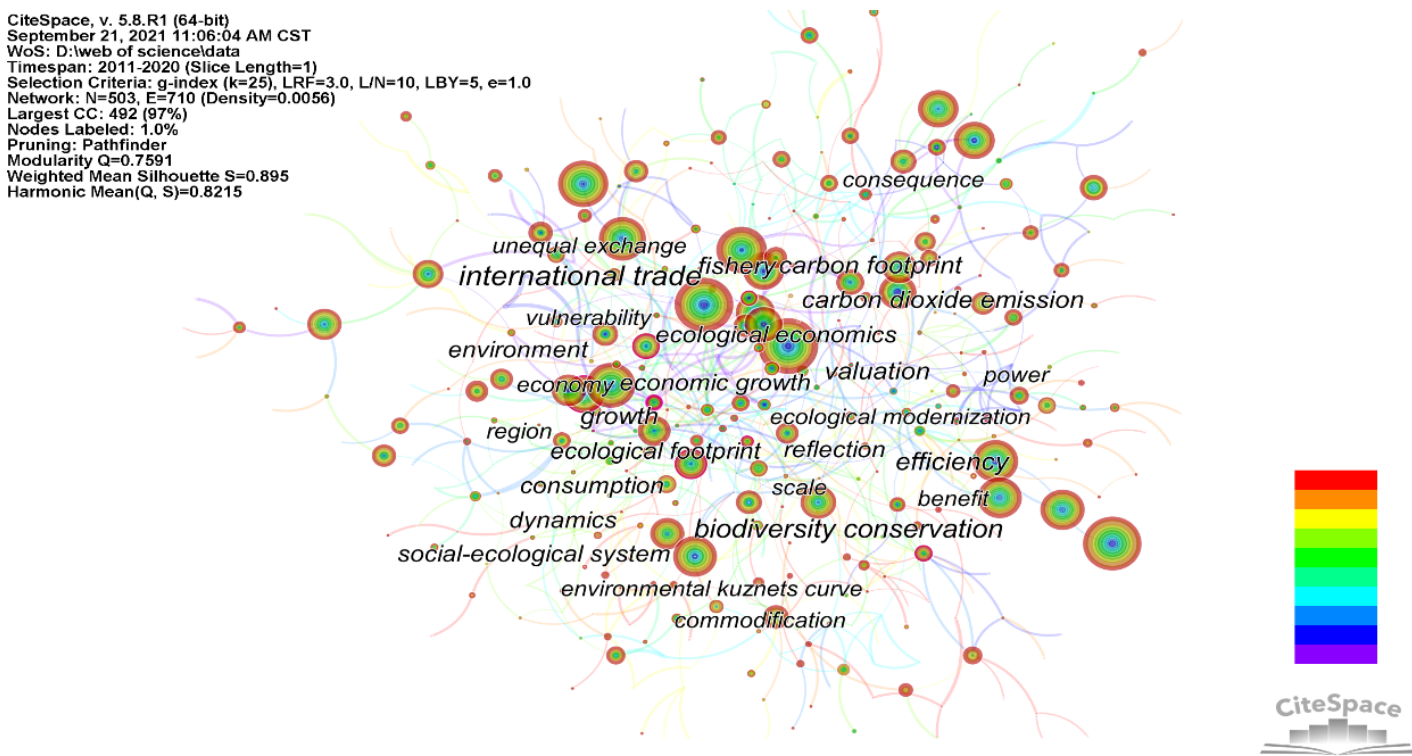

Figure 2. The co-occurrence map of keywords in the research field of ecological economy from 2011 to 2020

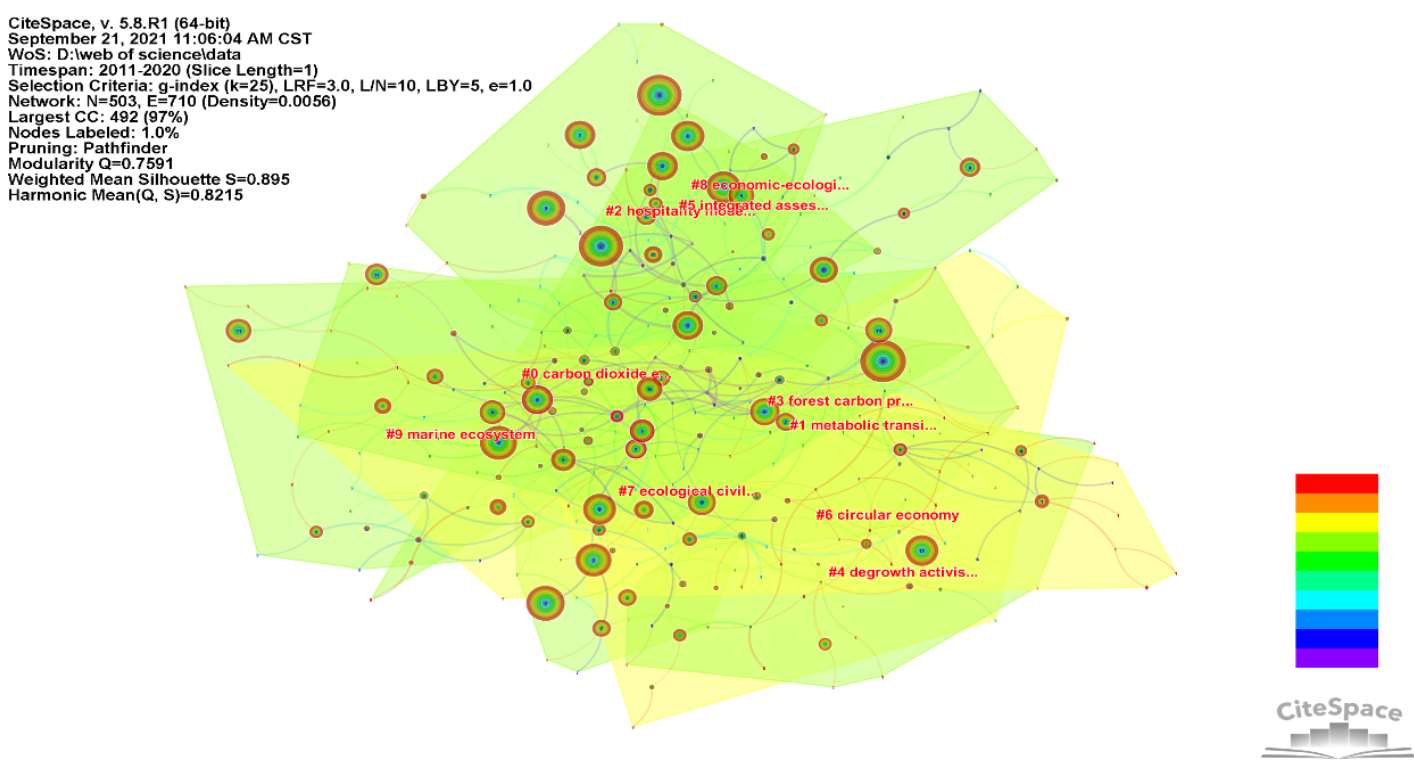

Figure 3. Clustering map of key nodes in the field of ecological economy research from 2011 to 2020

solve social, economic, and environmental development issues in an integrated manner, thereby turning to the path of sustainable development. Due to the efforts of the United Nations Sustainable Development Goals (SDGs-6, $7,8,12$, and 13), these goals have solved the problems of clean water, energy access, responsible consumption, and climate change mitigation ${ }^{[17]}$. The keyword emergence intensity cluster map (Figure 4) selects the emergence intensity of the first 22 keywords for analysis. According to the keyword emergence intensity cluster map (Figure 4), the keyword "ecological economics" (2011-2016) has the longest emergence time, indicating that the research enthusiasm for "ecological economics" lasts the longest. Among them, it is worth noting that the keyword "industrial ecology" appeared in 2012. The concept of industrial ecology first appeared in the 1989 "Scientific American" magazine. While mankind vigorously develops economy and technology, the problems of resource shortage and industrial pollution have also followed, restricting the development of human society. Industrial Ecology (IE) is a theory about the concept and implementation of sustainable development. In the past thirty years, scholars have conducted a lot of theoretical and applied research on IE. Especially in the past ten 
years, a large number of papers have been published in the field of industrial ecology, and the cooperation between authors has become more extensive, and there are clearer and more specific research contents and methods for industrial ecology. In recent years, China has gradually paid attention to research in this field ${ }^{[18]}$. The field of ecological economy has been in the development stage from 2011 to 2020, judging from the keyword timeline map (Figure 5). The rapid development stage began in 2016, and keywords in many aspects, such as energy use, product, natural resource, productivity, etc., appeared. The emergence of these keywords indicates that the current ecological economy research mainly focuses on high quality development. Humans and nature are repaying the

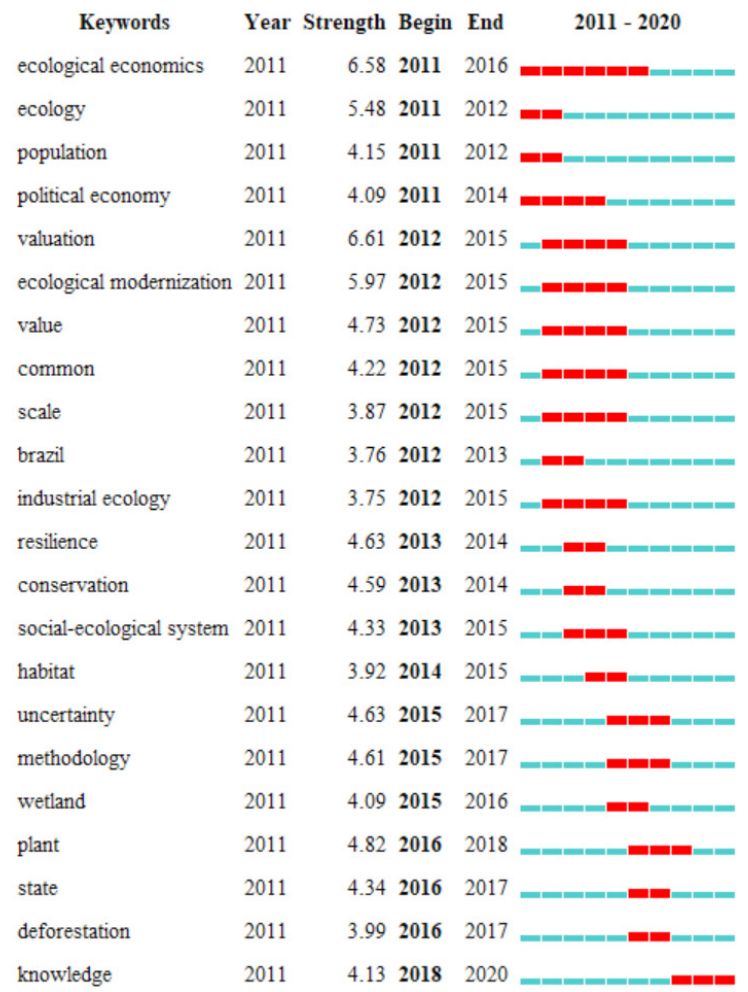

Figure 4. The cluster map of keyword emergence intensity in the research field of ecological economy from 2011 to 2020

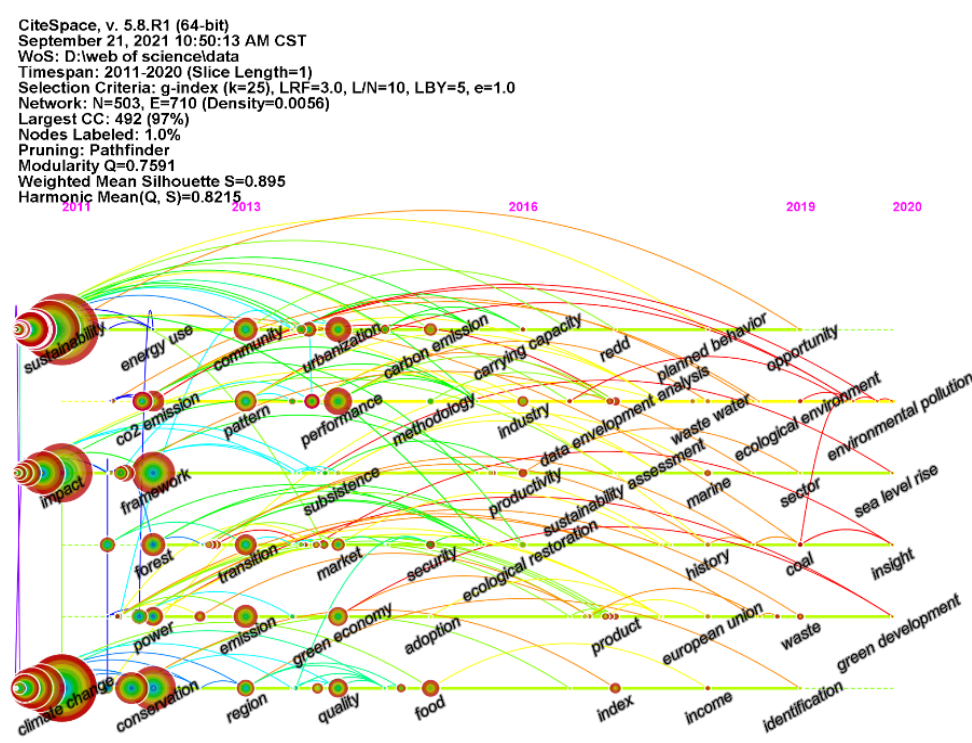

\#0 sustainability

\#1 efficiency

\#2 sustainable deve..

\#3 transition

\#4 degrowth

\#5 resilience

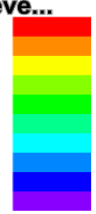

Figure 5. Timeline map of keywords in the research field of ecological economy from 2011 to 2020 
opportunity cost of economic development by accelerating the world's environmental degradation. The best choice to control and reduce environmental degradation to achieve sustainable development is to explore renewable energy ${ }^{[19]}$. The concept of sustainable development was proposed in the 1980s. Since its emergence, the concept has achieved great success ${ }^{[20]}$.

\subsection{Analysis of Research Institutions}

Based on the CiteSpace software, we obtained a cooperation map of institutions that published articles on ecological economics from 2011 to 2020. Each node in the graph represents an institution. The larger the node, the higher the institution's citation count. Institutions that publish documents in this field include the Chinese Academy of Sciences, Nanjing University, and other institutions. The top ten institutions are the Chinese Academy of Sciences, Beijing Normal University, University of Chinese Academy of Sciences, Peking University, University of Queensland, Stockholm University, Univ Autonoma, Barcelona, Russian Acad Sci, Univ British Columbia and Tsinghua Univ. Among them, the most cited institution is the Chinese Academy of Sciences, with a citation count of 149 , indicating that the research field of this institution is a research hotspot. Moreover, we found that compared with other countries, the literature published on "eco-economy" is mainly concentrated in related institutions in China, and the number of documents published by foreign institutions is relatively small. In addition, according to the network map of cooperative institutions in this field (Figure 6), there are 398 nodes, 343 connections, and a density of 0.0043 , indicating that the cooperation between the various institutions in the field of ecological economics is not close enough. The cooperation between organizations needs to be strengthened, which is conducive to promoting the development of the ecological economy. The result analysis shows that the institution with the largest number of documents published in the field of "eco-economy" is the Chinese Acad Sci; comparing with foreign countries, relevant institutions in China have published more "ecoeconomy" documents, and the partnership is not close enough.

\subsection{Analysis of Authors}

By importing the data into CiteSpace software for analysis, a network map of authors' cooperation in the field of the ecological economy was obtained (Figure 7). Our results shows that there are more authors published in the field of ecological economics, among which the author with the highest citation counts are YONG GENG, FRIDOLIN KRAUSMANN and WEI WANG, all with a citation count of 5 , indicating that they are influential scholars in this field. The fourth author is YU ZHANG, with 4 citations. There are more scholars in ecological economics, but there are fewer teams with close collaboration between authors. The connections in the figure indicate the cooperation among scholars. The
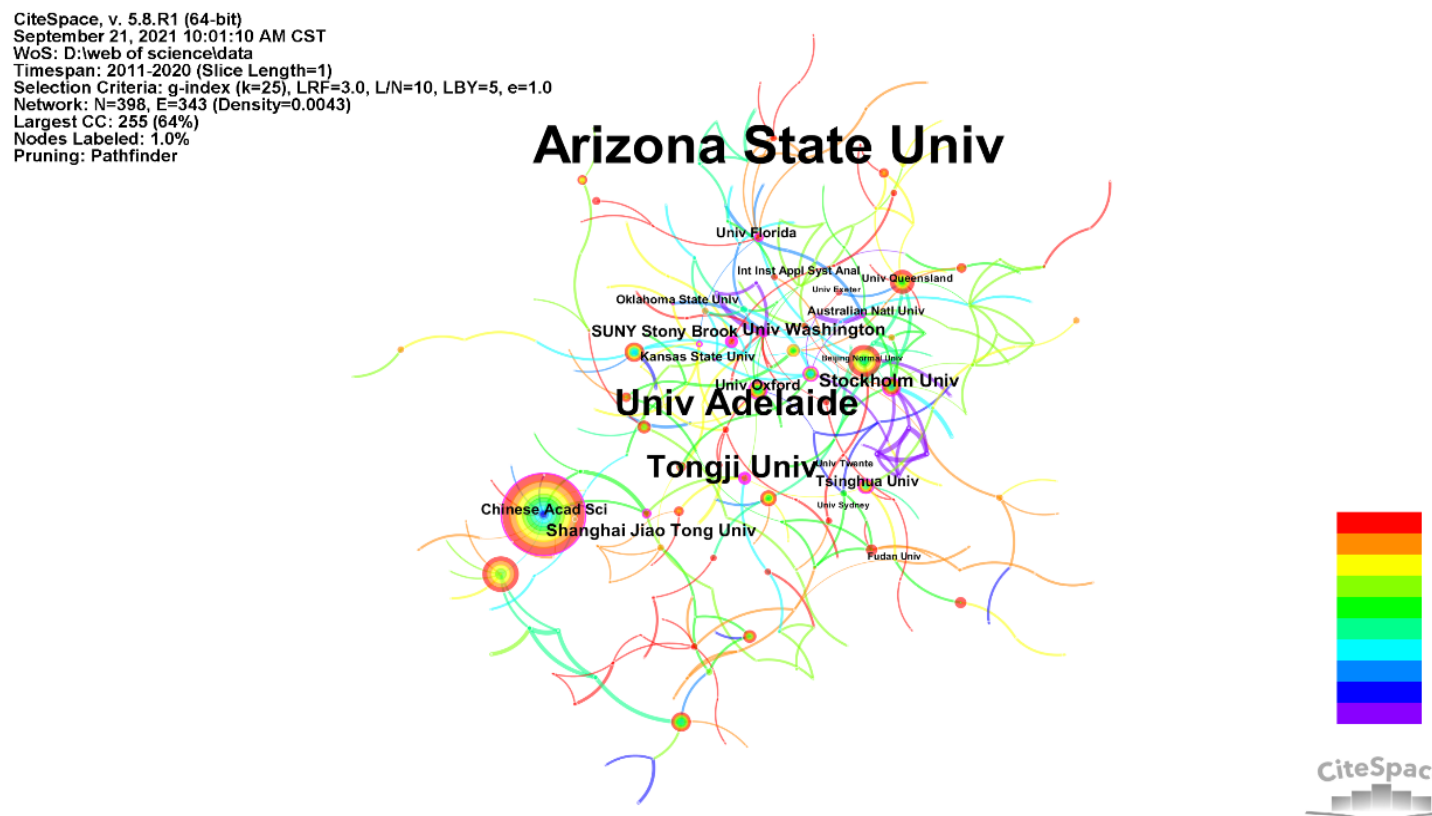

Figure 6. The network map of cooperation between institutions in the ecological economy research field from 2011 to 2020 


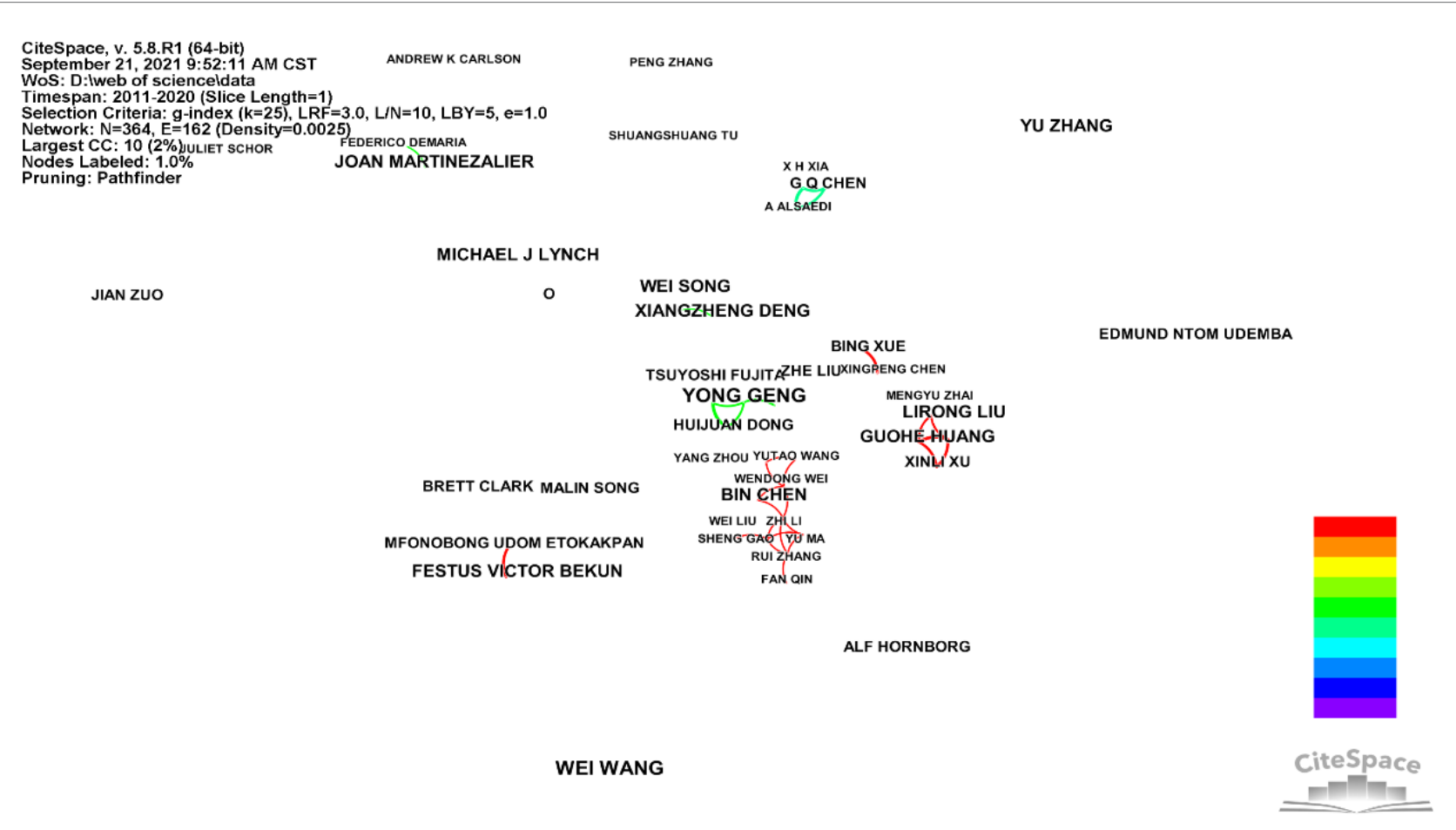

Figure 7. The network map of authors' cooperation in the field of ecological economy from 2011 to 2020

largest cooperative group is a 10-person team such as Fan qin, Yu Ma, Rui Zhang, Wei Liu, Yang Zhou, and Big Chen. We found that cooperation within the group and inter-group cooperation was less.

\section{Conclusions and Prospect}

Based on Web of Science (WoS) to retrieve English literature in the field of ecological economics, using bibliometric methods, CiteSpace software was used to analyze the research progress in ecological economics from 2011 to 2020, and analyze the research hotspots, institutions, authors, etc. in this field.

From a research perspective, researchers and related institutions play an essential role in ecological economy research. Judging from the number of documents issued, it has grown rapidly since 2011. Based on the analysis of the cooperation network of authors and institutions, the relationship between authors and institutions is inadequate, and cooperation density is poor. We found that China is the leader in ecological economics research, and related institutions in China have published many "ecological economy" documents. The Chinese Academic Science University is the leading research institution and biggest publisher of ecological economics documents. However, the closeness of cooperation between research institutions in the "eco-economy" is small, and the citation frequency of papers is relatively low, which has little effect on the promotion of research in ecological economics. The most productive authors in ecological economics are YONG GENG, FRIDOLIN KRAUSMANN and WEI WANG, etc. However, the paper has a low frequency of citations and little influence.

From the perspective of research hotspots, related articles on the ecological economy have diverse research perspectives, but they need to be expanded and deepened. Through keyword co-occurrence analysis, the top seven research hotspots in ecological economics include carbon dioxide emission, metabolic transition, hospitality model, forest carbon project, degrowth activist and circular economy indicating that the current research is mainly focused on sustainable development. From the perspective of overall changes in research hotspots, we found that the current research hotspots in ecological economics are sustainable development and high-quality development; the areas of concern are also more extensive. Paying close attention to the issue of carbon dioxide emissions and looking for a sustainable development model.

Based on Research Frontiers' perspective, research on the ecological economy from 2011 to 2014 mainly focused on $\mathrm{CO}_{2}$ emissions, energy use, political economy, and evaluation methods of ecological economics. The Frontier hot topics from 2015 to 2019 changed to plant, state, methodology, etc., after which more words emerged. The research is microscopic, and the objects are changed to financial development and metabolism, which appeared in 2019. These aspects are still researched, proving that 
it has practical significance. In terms of burst intensity, ecological economics has the highest burst intensity, and valuation, common, industrial ecology, etc. ranks second. According to the research data, the burst all started in 2012.

Currently, the development of ecological economics is still the main concern of humankind. The environment is a frontier topic. Environmental sustainability has attracted much attention, and there are many sustainable development concepts in the economic field ${ }^{[21]}$. This field is in a stage of rapid development. There is an upward trend in research fever among scholars in ecological economics, with increasing research results and a significant increase in the number of scientific research papers. From 2011 to 2020, 3074 articles were published. Combined with the visual analysis of research in the field of ecological economics, this article proposes the following research prospects:

(1) Strengthen exchanges and cooperation between institutions and scholars. In the context of society's close attention to the development of ecological economics, researchers and institutions should strengthen research cooperation, continuously improving their scientific research quality and use the knowledge spillover effect to carry out cross-regional and interdisciplinary research cooperation.

(2) Strengthen research based on the value of ecological economics. The value of ecological economics depends on its development method, which depends on the function of each ecosystem, and the function of the ecosystem depends on the structure of the ecosystem. Therefore, to strengthen the study of ecological economic value, it is necessary to analyze the structure of the ecological system, explore its functions, and outline the composition of ecological economic value through the establishment of an index system. In-depth understanding of the impact of different ecosystems on the development of ecological economy, the function of the ecosystem and the construction of an index system of ecological economic value is needed.

(3) Ecosystems include farmland, forest, and grassland ecosystems. These ecosystems provide ecological services to humans. Various ecosystems are interconnected. They promote, and restrict each other. When a particular ecosystem is destroyed, it is difficult for other ecosystems to keep evolving. Therefore, further research requires a broader perspective, and an in-depth study of the interactions between various ecosystems is necessary.

\section{Acknowledgement}

This research was funded by the National Research
Foundation of China (32160310 and 41661070); National Key Research and Development Program of China (2016YFD0300208); Scientific Project of Department of Jiangxi Education of China (GJJ200444); Key disciplines (construction) of ecology in the $13^{\text {th }}$ Five-Y ear Plan of Jiangxi Agricultural University.

\section{References}

[1] Wang SJ. A Few Basis Points of the Ecological Economy. Advanced Materials Research, 2015, 3702: 2871-2874.

[2] Jiang CX: Study on the Accelerated Establishment of a Legal Ecological Civilization System in the "New Normal" Economy. Lee G, Wu Y, editor, 2015 3rd International Conference on Social Science and Humanity, 2015: 503-507.

[3] Bockman J. The Long Road to 1989: Neoclassical Economics, Alternative Socialisms, and the Advent of Neoliberalism. Radical History Review, 2012, 2012(112) : 9-42.

[4] Thomas PD. Only One Earth: The Care and Maintenance of a Small Planet. By Barbara Ward and Rene Dubos. (New York: Ballantine Books, Inc., 1973. 288 pp. Index. Paper. \$1.50.). Forest \& Conservation History,1973,17(3):37-38.

[5] Rome A. Only One Earth: The Care and Maintenance of a Small Planet. Nature, 2015, 527(7579): 443-445.

[6] Rojstaczer S, Sterling SM, Moore NJ. Human Appropriation of the Products of Photosynthesis. BioScience, 1986, 36(6):368-373.

[7] Costanza R, Daly HE. Towardanecological economics. Ecological Modelling, 1987, 38(1-2): 1-7.

[8] Zhu WC, Liu S. Evaluationandanalysis of coordinateddevelopment of ecological environment andeconomy. Fresenius Environmental Bulletin, 2021, 30(5): 4798-4803.

[9] Clark CW. The economics of overexploitation. Science, 1973,181(4100): 630- 634.

[10] Chen SY. The evaluation indicator of ecological development transition in China's regional economy. Ecological Indicators, 2015, 51: 42-52.

[11] Shi T. Ecological economics as a policy science: rhetoric or commitment towards an improved decision-making process on sustainability. Ecological Economics, 2003, 48(1) : 23-36.

[12] Melgar-Melgar RE, Hall CAS. Why ecological economics needs to return to its roots: The biophysical foundation of socio-economic systems. Ecological Economics, 2020, 169.

[13] Xu MY, Chen CT, Deng XY. Systematic analysis of the coordination degree of China's economy-ecolog- 
ical environment system and its influencing factor. Environmental Science and Pollution Research, 2019, 26(29): 29722-29735.

[14] Ozkaynak B, Devine P, Rigby D. Whither ecological economics?. International Journal of Environment and Pollution, 2002, 18(4): 317-335.

[15] Estoque RC. A Review of the Sustainability Concept and the State of SDG Monitoring Using Remote Sensing. Remote Sensing, 2020, 12(11): 1770.

[16] Karobliene V. The Sharing Economy in the Framework of Sustainable Development Goals: Case of European Union Countries. Sustainability, 2021, 13(15): 8312.

[17] Fatima T, Meo MS, Bekun FV, et al. The impact of energy consumption to environmental sustainability: an extension of foreign direct investment induce pollution in Vietnam. International Journal of Energy Sector Management, 2021.
[18] Han F, Feng Z, Wang C, et al.Interweaving industrial ecology andecological modernization: AComparative Bibliometric Analysis Sustainability, 2021, 13(17): 9673.

[19] Ullah A, Ahmed M, Raza SA, et al. A threshold approach to sustainable development: Nonlinear relationship between renewable energy consumption, natural resource rent, and ecological footprint. Journal of Environmental Management, 2021, 295(5): 113073 .

[20] Bettencourt LMA, Kaur J. Evolution and structure of sustainability science. Proceedings of the National Academy of Sciences of the United States of America, 2011, 108(49): 19540-19545.

[21] Sun XS. Green city and regional environmental economic evaluation based on entropy method and GIS. Environmental Technology \& Innovation, 2021, 92(9): 101667. 